\title{
Off-label use of erectile dysfunction medication to enhance sex among gay and bisexual men in Australia: Data from the Flux study
}

Mohamed A. Hammoud, BPsy (Hons) a (mhammoud@kirby.unsw.edu.au)

Fengyi Jin, PhD a (jjin@kirby.unsw.edu.au)

Toby Lea, PhD ${ }^{\text {b }}$ (toby.lea@unsw.edu.au)

Lisa Maher, PhD a (lmaher@kirby.unsw.edu.au)

Jeffrey Grierson, PhD c (jeffrey.grierson@anglia.ac.uk)

Garrett Prestage, $\mathrm{PhD}^{\text {a }}$ (gprestage@kirby.unsw.edu.au)

${ }^{a}$ The Kirby Institute, UNSW Australia. Level 6, Wallace Wurth Building, UNSW Australia, Kensington NSW 2052 Australia

${ }^{\mathrm{b}}$ Centre for Social Research in Health, UNSW Australia, Kensington NSW 2052

c Anglia Ruskin University, Cambridge Campus, Cambridge CB1 1PT, United Kingdom

\section{Author Agreement/Declaration}

All authors certify that they have seen and approved the final version of the manuscript being submitted. All authors warrant that the article is the authors' original work, hasn't received prior publication and isn't under consideration for publication elsewhere.

\section{Conflict of interest}

All authors certify that they do not have actual or potential conflict of interest including any financial, personal, or other relationships with other people or organizations within three years of beginning the submitted world that could inappropriately influence, or be perceived to influence, their work. 
Off-label use of erectile dysfunction medication to enhance sex among gay and bisexual men in Australia: Data from the Flux study

\begin{abstract}
Introduction: Gay and bisexual men (GBM) use erectile dysfunction medications (EDM) such as Viagra ${ }^{\mathrm{TM}}$, Cialis ${ }^{\mathrm{TM}}$ and Levitra ${ }^{\mathrm{TM}}$ often with little evidence of medical indication that might necessitate their use.
\end{abstract}

Aim: We investigate the prevalence and contexts of, and motivations for, EDM use, and its relationship to sexual risk behavior.

Method: Between September 2014 and July 2015, Australian GBM were invited to enroll online through social networking and gay community sites to complete a comprehensive survey looking at licit and illicit drug use and their associated behaviors. A total of 2250 GBM completed the questionnaire.

Main outcome measures: Any EDM use, and at least weekly use in the previous six months.

Results: Two thirds (67.7\%) reported no history of EDM use in their lifetime. Approximately one in ten participants (11.1\%) had last used EDM more than six months ago. In the previous six months, $11.5 \%$ reported using EDM less than monthly, 5.3\% at least monthly, and 4.5\% weekly or more often. Among men who had used EDM in the previous six months, the most common reasons cited for its use were: to maintain an erection for longer (73.3\%), to make it easier to get hard (67.3\%), and difficulty in attaining or maintain an erection (53.5\%).

Conclusion: While some GBM use EDM specifically for erectile dysfunction, many also use EDM to enhance their sexual experiences. Often, this occurs in the context of intensive sex partying, which may include risky sexual behavior. The use of EDM in the context of intensive sex partying (which include the combined use of EDM and illicit drugs), with the 
associated potential for increased risk of HIV transmission, indicates a need to consider the use of EDM among GBM in HIV prevention

Key words: Viagra, Cialis, Levitra, Erectile dysfunction medication, Off-label use, Gay and bisexual men, Intensive sex partying, HIV risk behaviors and transmission. 


\section{Introduction}

Gay and bisexual men (GBM) use erectile dysfunction medications (EDM) such as Viagra ${ }^{\mathrm{TM}}$, Cialis $^{\mathrm{TM}}$ and Levitra ${ }^{\mathrm{TM}}$ often with little evidence of medical indication that might necessitate their use [1-5]. EDM were developed to treat medically diagnosed erectile dysfunction [6], which currently affects more than 150 million men worldwide [7]. Despite this, EDM have also been used recreationally particularly among GBM [4, 5, 8]. Off-label use of EDM are sometimes used to counter the effects of other illicit recreational drugs [9] and/or to enhance sexual experiences among GBM [4, 10]. EDM use, particularly combined with illicit drug use (such as amyl nitrite, gamma hydroxybutyrate (GHB) and crystalline methamphetamine) have been implicated in the transmission of sexually transmissible infections (STI), including HIV, due to higher levels of sexual risk behaviors [2, 11-14].

Intensive sex partying has been described as a combination of several factors that are associated with the risk of HIV infection [15]. These include: being very sexually active; being closely involved in gay community social and sexual networks; engaging in group sex; engaging in CLAI; and using party drugs [15]. EDM use for intensive sex partying has been associated with sexual risk behaviors [3, 4], such as increased numbers sex partners [2] and condomless anal intercourse (CLAI)[14]. GBM’s sexual practices are influenced by shared understandings of HIV risk and gay community norms [16]. This may also be true of druguse behaviors - namely off-label use of EDM.

Despite its role in HIV risk behaviors and transmission, few studies have described the characteristics of GBM who use EDM, the frequency of their use, and their motivations for using EDM. In this paper, we use baseline data from a cohort of Australian GBM to investigate the prevalence and contexts of, and motivations for, EDM use, and its relationship to sexual risk behavior. 


\section{Methods}

\section{Procedures}

The Following Lives Undergoing Change (Flux) Study is an online prospective observational study of Australian GBM. The methods are described in greater detail elsewhere [17]. In brief, participants were recruited between August 2014 and July 2015 via gay community websites and online media, Facebook, mobile phone applications, and gay sexual networking websites. Ethical approval was provided by the Human Research Ethics Committee of UNSW Australia.

\section{Measures}

The online baseline questionnaire included: demographic items, questions on sexual identity, HIV testing history and self-reported serostatus, sexual behavior with men, and attitudes and beliefs about drug use. Men described their lifetime and recent (i.e. previous six months) use of licit and illicit drugs, as well as the frequency and methods of use of EDM in the previous six months. They were also asked about the reasons for their use of EDM, including whether they used it to 'enhance sex'. We also included measures of social engagement with gay men [18] and of sexual sensation-seeking [19]. The generalized anxiety disorder assessment (GAD7) [20], and the patient health questionnaire (PHQ9)[21] were also included. To address intensive sex partying [15], we included questions about group sex, using drugs for sex or to enhance sex ('party and play’ or 'chemsex').

\section{Participants and sample}

Men who lived in Australia, aged sixteen years and six months or above, were eligible for participation if they identified as gay or bisexual or had sex with another man in the previous 
year. Overall, 4,306 people clicked on the study website, and 2,943 completed the online consent form; 2,250 completed the minimum data requirements for the online questionnaire.

\section{Analysis}

Descriptive statistics were used to characterize the types of men who used EDM. For univariate analyses of whether they had used EDM in the previous six months, and, separately, of whether they had used EDM at least weekly, we included: age, education, cultural background, social engagement with gay men, sexual identification, relationship status, HIV status, and sexual risk behavior. Categorical variables were analyzed using Pearson's chi-square test and t-tests were used for continuous variables. We used Type I error of $5 \%$ for these analyses. To estimate statistical associations, we used logistic regression models and presented Adjusted Odds Ratios (aOR) and 95\% Confidence Intervals (CI). Associations with a p-value of less than 0.10 in univariate analyses were included in the multivariate analyses. Data were analyzed using SPSS $^{\mathrm{TM}}$ version 23 software.

\section{Results}

\section{Characteristics of the sample}

The mean age of the 2,250 men was 33.0 years (SD 12.7). Over half of participants (52.4\%) were university educated. Almost half were in managerial (15.5\%) or professional (26.8\%) employment (Table 1). Participants predominantly identified as gay or homosexual (88.4\%), 8.8\% identified as bisexual and 2.7\% identified as either heterosexual or other. Most participants were of Anglo-Celtic background (72.0\%). Most men had been tested for HIV (80.3\%) with 7.6\% reporting that they were HIV-positive. Half (50.4\%) indicated they were in a relationship with another man, 25.9\% reported that most of their friends were gay men and $18.4 \%$ spent much of their free time with gay friends. 


\section{TABLE 1}

About a quarter (26.2\%) of men reported having more than ten male sex partners in the previous six months (Table 2). One third (35.4\%) had had sex with a 'fuckbuddy', over half with a casual partner (59.5), and 33.4\% with a 'boyfriend'. About a quarter reported CLAI with their boyfriend, and about one in twenty reported CLAI with any fuckbuddies or with any casual partners.

\section{TABLE 2}

\section{Prevalence}

Two thirds (67.7\%) reported no history of EDM use in their lifetime. Approximately one in ten participants (11.1\%) had last used EDM more than six months ago. In the previous six months, 11.5\% reported using EDM less than monthly, 5.3\% at least monthly, and 4.5\% weekly or more often (Table 1). Of those who used EDM in the previous six months, the types were: sildenafil citrate (88.3\%); tadalafil (76.2\%); and vardenafil (19.0\%). The majority (55.0\%) reported obtaining the medication other than by a prescription from a doctor, with the most common method being online procurement (33.8\%), followed by a casual male sex partner (17.9\%) and a regular fuckbuddy (15.6\%).

The majority (68.8\%) reported having used illicit drugs in the previous six months, with amyl nitrite (52.9\%), cannabis (35.4\%), and crystalline methamphetamine (32.4\%) being the most common drugs reported (Table 2). Among those who used illicit drugs, 55.6\% reported having used 'party drugs to enhance their sexual experiences’.

\section{Univariate associations}

Those who were older used EDM more recently $(\mathrm{p}<0.001)$ and more often $(\mathrm{p}<0.001$; Table 1). Men who ever used EDM had higher levels of education. Approximately one in five men 
who had used EDM were HIV-positive. HIV-positive men were more likely to have ever used EDM $(\mathrm{p}<0.001)$, whereas untested men were less likely to have ever used EDM $(\mathrm{p}<0.001)$. Most $(82.2 \%)$ of those who used EDM in the previous six months reported having at least some friends who also used EDM, while 76.9\% of the men who never used EDM reported also having no friends who used EDM. Men who had recently used EDM were more socially engaged with other gay men $(\mathrm{p}=0.013)$ and they also had higher scores on the measure of sexual sensation seeking $(\mathrm{p}=0.022)$.

The more recently, and more frequently, men used EDM the greater the number of sexual partners they were likely to report in the previous six months, and the more likely they were to have had sex both with fuckbuddies and with casual partners (Table 2). More recent and frequent EDM users were also more likely to report CLAI with these partner types; nearly half (42.6\%) of men who used EDM weekly reported CLAI with fuckbuddies, and half (56.4\%) reported CLAI with casual partners. The more recently, and more frequently, men used EDM, the more likely they were to report having engaged in group sex in the previous six months.

Those who used EDM more frequently were significantly more likely to use most illicit drugs compared to those who used EDM less frequently or did not use EDM (Table 2). Those who had used illicit drugs to enhance sexual pleasure were more likely to report recent EDM use than were those who had not used them for this purpose.

\section{Reasons for use}

Among men who had used EDM in the previous six months, the most common reasons cited for its use were: to maintain an erection for longer (73.3\%), to make it easier to get hard (67.3\%), and difficulty in attaining or maintain an erection (53.5\%; Table 3). GBM who used EDM weekly or more often were more likely to cite the need to maintain an erection for 
longer and to make it easier to get hard as reasons for its use. Those who used EDM monthly or less frequently in the previous six months were likely to cite 'fun' and the need to counter the effects of other drugs as reasons for its use.

\section{TABLE 3}

Covariates of EDM use in the previous six months

In univariate analyses, GBM who were older, of Anglo-Celtic background, had higher education, were not in a relationship, were HIV-positive, and were more socially engaged with gay men, were significantly more likely to have used EDM in the previous six months (Table 4). EDM use in the previous six months was also associated with lower scores on the PHQ9 and GAD scales, higher scores on the sexual sensation seeking scale, having more sex partners, having group sex, reporting CLAI with casual partners and fuckbuddies, and using 'party drugs' to enhance sex.

In the multivariate analysis, being older, being HIV positive, being more socially engaged with gay men, scoring higher on the sexual sensation seeking scale, having engaged in group sex, engaging in CLAI with fuckbuddies, and using drugs to enhance sex were independently associated with EDM use in the previous six months (Table 4).

\section{Covariates of weekly or more frequent EDM use}

In univariate analyses, GBM who were older, of Anglo-Celtic background, and were not in a relationship were significantly more likely to have used EDM weekly compared to those who used less frequently in the previous six months (Table 4). Weekly or more frequent use of EDM was also associated with CLAI with casual partners and using drugs to enhance sex. 
In a multivariate analysis, being older, higher education, and having engaged in CLAI with casual partners were independently associated with weekly EDM use in the previous six months (Table 4).

\section{TABLE 4}

\section{Concurrent polydrug use with EDM}

In a separate multivariate analysis looking only at concurrent polydrug use with EDM, any use of EDM in the previous six months was independently associated with use of amyl nitrite $(\mathrm{aOR}=2.58 ; 95 \%=2.01-3.30 ; \mathrm{p}<0.001), \mathrm{GHB}(\mathrm{aOR}=3.36 ; 95 \%=2.19-5.12 ; \mathrm{p}<0.001)$, and crystalline methamphetamine $(\mathrm{aOR}=3.52 ; 95 \%=2.51-4.92 ; \mathrm{p}<0.001)$.

\section{Discussion}

The majority of men in the Flux study had never used EDM. Men who used EDM more recently and more frequently tended to be somewhat older. The age distribution of EDM was similar to what has been found elsewhere in that older men were more likely to use EDM, and to use it more frequently [12].Those who used EDM recently were significantly more likely than non-users to socialize with friends who also used EDM.

Although EDM use is intended to treat erectile dysfunction, many men also use EDM without having such a medical condition [1-5]. Nonetheless, it is likely that those who do experience erectile dysfunction would tend to use EDM on a regular basis. The age distribution of EDM was similar to what has been found elsewhere in that older men were more likely to use EDM, and to use it more frequently [12]. The reasons men gave for their use of EDM appear to support this. While both weekly and less frequent users of EDM cited 'maintaining an erection' and 'make it easier to get hard' as reasons for their EDM use, those who used EDM at least weekly cited 'difficulty in attaining or maintaining an erection' as a reason for their EDM use. 
In this sample, EDM appeared to be used primarily to enhance aspects of intensive sex partying, for such purposes as: To maintain an erection for longer and to counter the effects of other drugs on the ability to attain and maintain an erection. Users of EDM were also more likely to engage in those practices that have been described as aspects of intensive sex partying. Our data support previous contention that in the context of intensive sex partying, GBM often use EDM, both to enhance and extend the sexual experience, and to counter the effects of other party drugs $[1,13]$. While some GBM, particularly those who use EDM weekly or more frequently, may do so for specific medical conditions involving erectile dysfunction, much of the use in our sample appears to be at least as often for 'recreational' as it is for therapeutic purposes.

Peer influence and social connection appear to be factors associated with the use of EDM by GBM. Those who were more socially engaged with other gay men were significantly more likely to use EDM. Overall, EDM use appears to be relatively common among GBM, and most of those who used EDM also reported having gay friends who also used it, suggesting that EDM use is fairly normalized among GBM. Less than one in five GBM who did not use EDM themselves reported having friends that used it. Additionally, more sexually active men and those who participated in intensive sex partying were particularly likely to report EDM use in the previous six months.

HIV-positive men tend to be older [22], and are more likely to be involved in subcultures where intensive sex partying occurs [15, 23], both of which are associated with EDM use. Regardless, self-reported HIV-positive status was not independently associated with weekly or more frequent EDM use. This suggests that the use of EDM for erectile dysfunction may be no more common among HIV-positive GBM than it is among other men, and that they are at least as likely to be using EDM recreationally. 
Men who used EDM in the previous six months reported fewer symptoms of anxiety and depression than those who did not use EDM. However, those who used EDM weekly or more often reported more symptoms of anxiety and depression than those who used less frequently. Our data provide no evidence of poor mental health among users of EDM overall, but those who use EDM on a more frequent basis may be subject to symptoms of anxiety and depression. Our data cannot determine whether these symptoms are related to their use of EDM or, possibly, to the reasons for their more frequent use of EDM. Those who used EDM more frequently were more likely to cite erectile dysfunction as a reason for their use of EDM, and erectile dysfunction has been associated with poor mental health outcomes [24, 25]. On the other hand, those men who use EDM less frequently appeared less likely to do so for therapeutic purposes and they tended to have lower scores on both depression and anxiety than either the men who used EDM at least weekly or the men who never used EDM.

\section{Limitations and strengths}

Participants in this study were broadly similar to other samples of Australian GBM [26, 27]. Nonetheless, it was a volunteer, online convenience sample and may not be representative of all GBM in Australia. Extrapolating these findings to other contexts may be limited by differences between Australia and other locations. Also, this was a cross-sectional analysis of baseline data from a cohort study and as such it is not possible to determine any causative or temporal relationships in the data.

The Flux Study is Australia’s first large-scale study specifically looking at drug use among GBM among whom prevalence is known to be higher than the general population. It includes comprehensive detailed data on history of use, and how and why men use drugs. Our large, community-based national sample is geographically dispersed and includes men of all ages and both those that are engaged and those not engaged with gay community life. Our online 
methodology potentially reduces social desirability bias in reporting illegal or stigmatised behaviours [28-30].

\section{Conclusion}

While some GBM use EDM specifically for erectile dysfunction, many also use EDM to enhance their sexual experiences. Often, this occurs in the context of intensive sex partying, which may include risky sexual behavior. GBM who use EDM also use illicit drugs at higher rates compared to those who do not use EDM. The use of EDM in the context of intensive sex partying (which include the combined use of EDM and illicit drugs), with the associated potential for increased risk of HIV transmission, indicates a need to consider the use of EDM among GBM in HIV prevention. Specifically, there is a need for health promotion initiatives with men who engage in intensive sex partying to address the potential of EDM to amplify the risk of STI, including HIV, transmission. These initiatives need to acknowledge the emic value of EDM within particular sexual cultures, its relationship to CLAI and how this may conflict with harm minimization approaches. 


\section{References}

1. Colfax, G.N., et al., Drug use and sexual risk behavior among gay and bisexual men who attend circuit parties: a venue-based comparison. JAIDS Journal of Acquired Immune Deficiency Syndromes, 2001. 28(4): p. 373-379.

2. Kim, A.A., C.K. Kent, and J.D. Klausner, Increased risk of HIV and sexually transmitted disease transmission among gay or bisexual men who use Viagra, San Francisco 2000-2001. AIDS, 2002. 16(10): p. 1425-1428.

3. Paul, J.P., D. Osmond, and J.A. Catania, Viagra (sildenafil) use in a population-based sample of US men who have sex with men. Sexually transmitted diseases, 2005. 32(9): p. 531-533.

4. Prestage, G., et al., Use of illicit drugs and erectile dysfunction medications and subsequent HIV infection among gay men in Sydney, Australia. The journal of sexual medicine, 2009. 6(8): p. 2311-2320.

5. Sherr, L., et al., Viagra use and sexual risk behaviour among gay men in London. Aids, 2000. 14(13): p. 2051.

6. Boolell, M., et al., Sildenafil: an orally active type 5 cyclic GMP-specific phosphodiesterase inhibitor for the treatment of penile erectile dysfunction. International journal of impotence research, 1996. 8(2): p. 47-52.

7. Jackson, G., H. Gillies, and I. Osterloh, Past, present, and future: a 7-year update of Viagra ${ }^{\circledR}($ sildenafil citrate). International journal of clinical practice, 2005. 59(6): p. 680-691.

8. Romanelli, F. and K.M. Smith, Recreational use of sildenafil by HIV-positive andnegative homosexual/bisexual males. Annals of Pharmacotherapy, 2004. 38(6): p. 1024-1030.

9. $\quad$ Fisher, D.G., et al., Recreational Viagra use and sexual risk among drug abusing men. American Journal of Infectious Diseases, 2006. 2(2): p. 107. 
10. Fisher, D.G., G.L. Reynolds, and L.E. Napper, Use of crystal meth, Viagra and sexual behaviour. Current opinion in infectious diseases, 2010. 23(1): p. 53.

11. Alpert, J.S., Viagra: the risks of recreational use. The American journal of medicine, 2005. 118(6): p. 569-570.

12. Crosby, R. and R. DiClemente, Use of recreational Viagra among men having sex with men. Sexually Transmitted Infections, 2004. 80(6): p. 466-468.

13. Hirshfield, S., et al., Substance use and high-risk sex among men who have sex with men: a national online study in the USA. AIDS care, 2004. 16(8): p. 1036-1047.

14. Swearingen, S.G. and J.D. Klausner, Sildenafil use, sexual risk behavior, and risk for sexually transmitted diseases, including HIV infection. The American journal of medicine, 2005. 118(6): p. 571-577.

15. Hurley, M. and G. Prestage, Intensive sex partying amongst gay men in Sydney. Culture, health \& sexuality, 2009. 11(6): p. 597-610.

16. Kippax, S., Sustaining safe sex: Gay communities respond to AIDS. 1993: Taylor \& Francis.

17. Hammoud, M.A., et al., Following Lives Undergoing Change (Flux) Study: Implementation and Baseline Prevalence of Drug Use in an Online Cohort Study of Gay and Bisexual Men in Australia. International Journal of Drug Policy, In Press.

18. Zablotska, I.B., M. Holt, and G. Prestage, Changes in gay men's participation in gay community life: implications for HIV surveillance and research. AIDS and Behavior, 2012. 16(3): p. 669-675.

19. Kalichman, S.C., T. Heckman, and J.A. Kelly, Sensation seeking as an explanation for the association between substance use and HIV-related risky sexual behavior. Archives of sexual behavior, 1996. 25(2): p. 141-154.

20. Spitzer, R.L., et al., A brief measure for assessing generalized anxiety disorder: the GAD-7. Archives of internal medicine, 2006. 166(10): p. 1092-1097. 
21. Kroenke, K., R.L. Spitzer, and J.B. Williams, The Phq-9. Journal of general internal medicine, 2001. 16(9): p. 606-613.

22. Prestage, G., et al., Homosexual men in Australia: population, distributionand HIV prevalence. Sexual Health, 2008. 5(2): p. 97-102.

23. Prestage, G., et al., Use of illicit drugs among gay men living with HIV in Sydney. Aids, 2007. 21: p. S49-S55.

24. Korfage, I.J., et al., Erectile dysfunction and mental health in a general population of older men. The journal of sexual medicine, 2009. 6(2): p. 505-512.

25. Tan, H.M., S.F. Tong, and C.C. Ho, Men's health: sexual dysfunction, physical, and psychological health—is there a link? The journal of sexual medicine, 2012. 9(3): p. 663-671.

26. Lea, T., et al., Trends in drug use among gay and bisexual men in Sydney, Melbourne and Queensland, Australia. Drug and alcohol review, 2013. 32(1): p. 39-46.

27. Roxburgh, A., et al., Sexual identity and prevalence of alcohol and other drug use among Australians in the general population. International Journal of Drug Policy, 2016. 28: p. 76-82.

28. Davis, R.E., et al., Interviewer effects in public health surveys. Health education research, 2010. 25(1): p. 14-26.

29. De Vaus, D., Surveys in social research. 2013: Routledge.

30. Engel, R.J. and R.K. Schutt, The practice of research in social work. 2016: Sage Publications. 
Table 1: Characteristics of sample according to use of erectile dysfunction medication. $\mathrm{N}=2250$

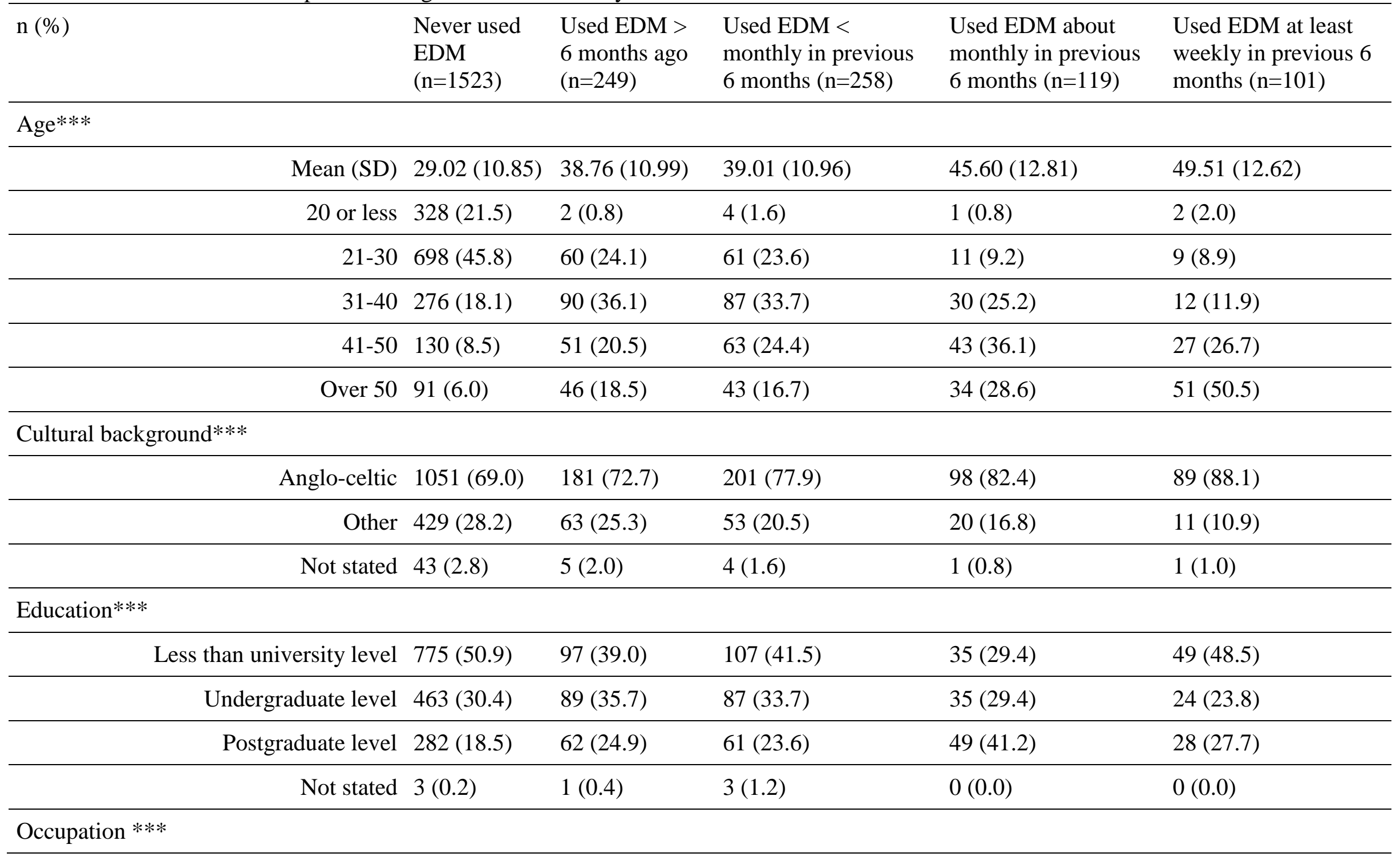




\begin{tabular}{|c|c|c|c|c|c|}
\hline Managerial & $205(13.5)$ & 49 (19.7) & $47(18.2)$ & $24(20.2)$ & $24(23.8)$ \\
\hline Professional & $362(23.8)$ & $90(36.1)$ & $80(31.0)$ & $45(37.8)$ & $26(25.7)$ \\
\hline Other white collar & $240(15.8)$ & $28(11.2)$ & 38 (14.7) & $11(9.2)$ & $10(9.9)$ \\
\hline Other & $150(9.8)$ & 34 (13.7) & $31(12.0)$ & $12(10.1)$ & $7(6.9)$ \\
\hline Not in work & $566(37.2)$ & 48 (19.3) & $62(24.0)$ & $27(22.7)$ & $34(33.7)$ \\
\hline \multicolumn{6}{|l|}{ HIV Status*** } \\
\hline HIV-positive & $36(2.4)$ & $36(14.5)$ & $52(20.2)$ & $30(25.2)$ & $17(16.8)$ \\
\hline HIV-negative & 1057 (69.4) & $205(82.3)$ & $194(75.2)$ & $87(73.1)$ & $79(78.2)$ \\
\hline Unknown/untested & $430(28.2)$ & $8(3.2)$ & $12(4.7)$ & $2(1.7)$ & $5(5.0)$ \\
\hline \multicolumn{6}{|l|}{ In a relationship with regular partner } \\
\hline Not in a relationship & $766(50.3)$ & $124(49.8)$ & $120(46.5)$ & $53(44.5)$ & $52(51.5)$ \\
\hline In a relationship & $757(49.7)$ & $125(50.2)$ & $138(53.5)$ & $66(55.5)$ & 49 (48.5) \\
\hline \multicolumn{6}{|l|}{ Mean (SD) } \\
\hline Gay social engagement $* * *$ & $3.16(1.59)$ & $3.94(1.54)$ & $4.04(1.51)$ & $4.53(1.47)$ & $4.32(1.70)$ \\
\hline $\begin{array}{l}\text { Generalized Anxiety Disorder (GAD-7) } \\
*\end{array}$ & $5.36(5.27)$ & $4.65(5.38)$ & 4.59 (4.68) & $4.01(4.60)$ & $4.65(5.71)$ \\
\hline $\begin{array}{l}\text { Patient Health Questionnaire (PHQ-9) } \\
*\end{array}$ & $7.34(6.20)$ & $6.52(6.40)$ & $6.33(5.89)$ & $5.92(5.75)$ & 6.65 (6.99) \\
\hline Sexual sensation-seeking $* * *$ & $28.2(6.47)$ & $30.0(5.84)$ & $31.0(5.78)$ & $32.8(5.65)$ & $32.0(6.44)$ \\
\hline
\end{tabular}


Table 2: Sexual behaviour and illicit drug use in previous 6 months according to use of erectile dysfunction medication. N=2250

\begin{tabular}{|c|c|c|c|c|c|}
\hline n (\%) & $\begin{array}{l}\text { Never used } \\
\text { EDM } \\
(n=1523)\end{array}$ & $\begin{array}{l}\text { Used EDM > } \\
6 \text { months ago } \\
(n=249)\end{array}$ & $\begin{array}{l}\text { Used EDM < } \\
\text { monthly in previous } \\
6 \text { months }(\mathrm{n}=258)\end{array}$ & $\begin{array}{l}\text { Used EDM about } \\
\text { monthly in previous } \\
6 \text { months }(\mathrm{n}=119)\end{array}$ & $\begin{array}{l}\text { Used EDM at least } \\
\text { weekly in previous } 6 \\
\text { months }(n=101)\end{array}$ \\
\hline \multicolumn{6}{|l|}{ Number of sexual partners $* * *$} \\
\hline Mean (SD) & $9.21(32.92)$ & $16.76(66.87)$ & $21.32(36.06)$ & $29.59(43.11)$ & $39.64(77.00)$ \\
\hline No partner & $207(13.6)$ & $24(9.6)$ & $8(3.1)$ & $1(0.8)$ & $2(2.0)$ \\
\hline Up to 10 & $979(64.3)$ & $143(57.4)$ & $108(41.9)$ & $60(50.4)$ & $56(55.4)$ \\
\hline Over 10 & $292(19.2)$ & $74(29.7)$ & $108(41.9)$ & $60(50.4)$ & $56(55.4)$ \\
\hline Not stated & $45(3.0)$ & $8(3.2)$ & $8(3.1)$ & $6(5.0)$ & $4(4.0)$ \\
\hline \multicolumn{6}{|l|}{ Sex with boyfriends } \\
\hline No boyfriend & $994(65.3)$ & $149(59.8)$ & 157 (60.9) & $64(53.8)$ & $6463.4)$ \\
\hline No anal intercourse & $37(2.4)$ & $6(2.4)$ & $9(3.5)$ & $3(2.5)$ & $3(3.0)$ \\
\hline Condom use only & $65(4.3)$ & $7(2.8)$ & $7(2.7)$ & $7(5.9)$ & $6(5.9)$ \\
\hline Any condomless anal intercourse & $382(25.1)$ & 79 (31.7) & $77(29.8)$ & $39(32.8)$ & $24(23.8)$ \\
\hline Not stated & $45(3.0)$ & $8(3.2)$ & $8(3.1)$ & $6(5.0)$ & $4(4.0)$ \\
\hline \multicolumn{6}{|l|}{ Sex with fuckbuddy *** } \\
\hline No fuckbuddies & $1040(68.3)$ & $143(57.4)$ & $118(45.7)$ & $44(37.0)$ & $38(37.6)$ \\
\hline No anal intercourse & $38(2.5)$ & $8(3.2)$ & $7(2.7)$ & $4(3.4)$ & $3(3.0)$ \\
\hline Condom use only & $167(11.0)$ & $26(10.4)$ & 35 (13.6) & $11(9.2)$ & 13 (12.9) \\
\hline
\end{tabular}




\begin{tabular}{|c|c|c|c|c|c|}
\hline Any condomless anal intercourse & $233(15.3)$ & $64(25.7)$ & 90 (34.9) & $54(45.4)$ & $43(42.6)$ \\
\hline Not stated & $45(3.0)$ & $8(3.2)$ & $8(3.1)$ & $6(5.0)$ & $4(4.0)$ \\
\hline \multicolumn{6}{|l|}{ Sex with casual partners $* * *$} \\
\hline No casual partners & $688(45.2)$ & 77 (30.9) & $41(15.9)$ & $19(16.0)$ & $14(13.9)$ \\
\hline No anal intercourse & $83(5.4)$ & $25(10.0)$ & $20(7.8)$ & $14(11.8)$ & $6(5.9)$ \\
\hline Condom use only & $378(24.8)$ & $59(23.7)$ & $73(28.3)$ & $31(26.1)$ & 20 (19.8) \\
\hline Any condomless anal intercourse & $329(21.6)$ & $80(32.1)$ & $116(45.0)$ & $49(41.2)$ & $57(56.4)$ \\
\hline Not stated & $45(3.0)$ & $8(3.2)$ & $8(3.1)$ & $6(5.0)$ & $4(4.0)$ \\
\hline \multicolumn{6}{|l|}{ Group sex $* * *$} \\
\hline No group sex & $1124(73.8)$ & $151(60.6)$ & $115(44.6)$ & $49(41.2)$ & $35(34.7)$ \\
\hline Any group sex & $310(20.4)$ & $83(33.3)$ & $129(50.0)$ & $63(52.9)$ & $58(57.4)$ \\
\hline Not stated & $89(5.8)$ & $15(6.0)$ & $14(5.4)$ & $7(5.9)$ & $8(7.9)$ \\
\hline \multicolumn{6}{|l|}{ Recent illicit drug use $^{1}$} \\
\hline *** No recent drug use & $345(22.7)$ & $50(20.1)$ & $26(10.1)$ & $9(7.6)$ & $14(13.9)$ \\
\hline *** Used amyl nitrite & $373(24.5)$ & $96(38.6)$ & 139 (53.9) & $65(54.6)$ & $49(48.5)$ \\
\hline *** Used cannabis & $412(27.1)$ & $80(32.1)$ & $100(38.8)$ & $37(31.1)$ & $32(31.7)$ \\
\hline$* * *$ Used ecstasy & $204(13.4)$ & $63(25.3)$ & 77 (29.8) & $33(27.7)$ & $20(19.8)$ \\
\hline *** Used meth/amphetamine (speed) & $69(4.5)$ & $25(10.0)$ & $26(10.1)$ & $7(5.9)$ & $8(7.9)$ \\
\hline$* * *$ Used cocaine & 135 (8.9) & $49(19.7)$ & $57(22.1)$ & $24(20.2)$ & $16(15.8)$ \\
\hline *** Used crystalline methamphetamine & $70(4.6)$ & $44(17.7)$ & $84(32.6)$ & $40(33.6)$ & $31(30.7)$ \\
\hline
\end{tabular}




\begin{tabular}{|c|c|c|c|c|c|}
\hline $\begin{array}{r}\text { *** Used gamma hydroxybutyrate } \\
\text { (GHB) }\end{array}$ & $31(2.0)$ & $21(8.4)$ & $53(20.5)$ & $31(26.1)$ & $20(19.8)$ \\
\hline *** Ketamine & $31(2.0)$ & $11(4.4)$ & $18(7.0)$ & $13(10.9)$ & 12 (11.9) \\
\hline ** Lysergic acid diethylamide (LSD) & $50(3.3)$ & $14(5.6)$ & $11(4.3)$ & $2(1.7)$ & $4(4.0)$ \\
\hline ** Heroin & $0(0.0)$ & $1(0.4)$ & $1(0.4)$ & $0(0.0)$ & $1(1.0)$ \\
\hline \multicolumn{6}{|l|}{ Used drugs to enhance sex $* * *$} \\
\hline Never & 1418 (93.1) & $192(77.1)$ & $164(63.6)$ & $68(57.1)$ & $63(62.4)$ \\
\hline Once & $39(2.6)$ & $25(10.0)$ & $15(5.8)$ & $9(7.6)$ & $4(4.0)$ \\
\hline More than once & $66(4.3)$ & 32 (12.9) & $79(30.6)$ & $42(35.3)$ & $34(33.7)$ \\
\hline
\end{tabular}

${ }^{*} \mathrm{p}<0.05 \quad * * \mathrm{p}<0.01 \quad * * * \mathrm{p}<0.001$

${ }^{1}$ Items are not mutually exclusive: Could have used multiple drugs 
Table 3: Reasons for use of erectile dysfunction medication in previous six month. $\mathrm{N}=478$

\begin{tabular}{llll}
\hline $\mathrm{n}(\%)$ & $\begin{array}{l}\text { Used EDM in the } \\
\text { previous six months } \\
\mathrm{n}=377(78.7)\end{array}$ & $\begin{array}{l}\text { Used EDM weekly in the } \\
\text { previous six months } \\
\mathrm{n}=(101) 21.3\end{array}$ & Total (n=478) \\
\hline To counter effects of other drugs & $153(40.6)$ & $32(31.7)$ & $185(38.7)$ \\
\hline To make condom use easier & $77(20.4)$ & $29(28.7$ & $106(22.2)$ \\
\hline To see what it was like *** & $64(17.0)$ & $1(1.0)$ & $65(13.6)$ \\
\hline To make it easier to 'get hard' $*$ & $200(53.1)$ & $68(67.3)$ & $268(6.1)$ \\
\hline Someone else wanted me to use it & $23(6.1)$ & $2(2.0)$ & $130(27.2)$ \\
\hline For fun *** & $120(31.8)$ & $10(9.9)$ & $304(63.6)$ \\
\hline To maintain erection longer $*$ & $230(61.0)$ & $74(73.3)$ & $171(35.8)$ \\
\hline $\begin{array}{l}\text { Difficulty attaining or maintaining erection } \\
* * *\end{array}$ & $117(31.0)$ & $54(53.5)$ & $75(15.7)$ \\
\hline Needs EDM to take insertive position $* *$ & $50(13.3)$ & & \\
\hline$* \mathrm{p}<0.05$ & & &
\end{tabular}


Table 4: Associations with use of erectile dysfunction medication.

Any use in the previous six months vs. no use in the previous six months. $\mathrm{N}=2250$

At least weekly use in the previous six months vs. less frequent use in the previous six months. $n=478$

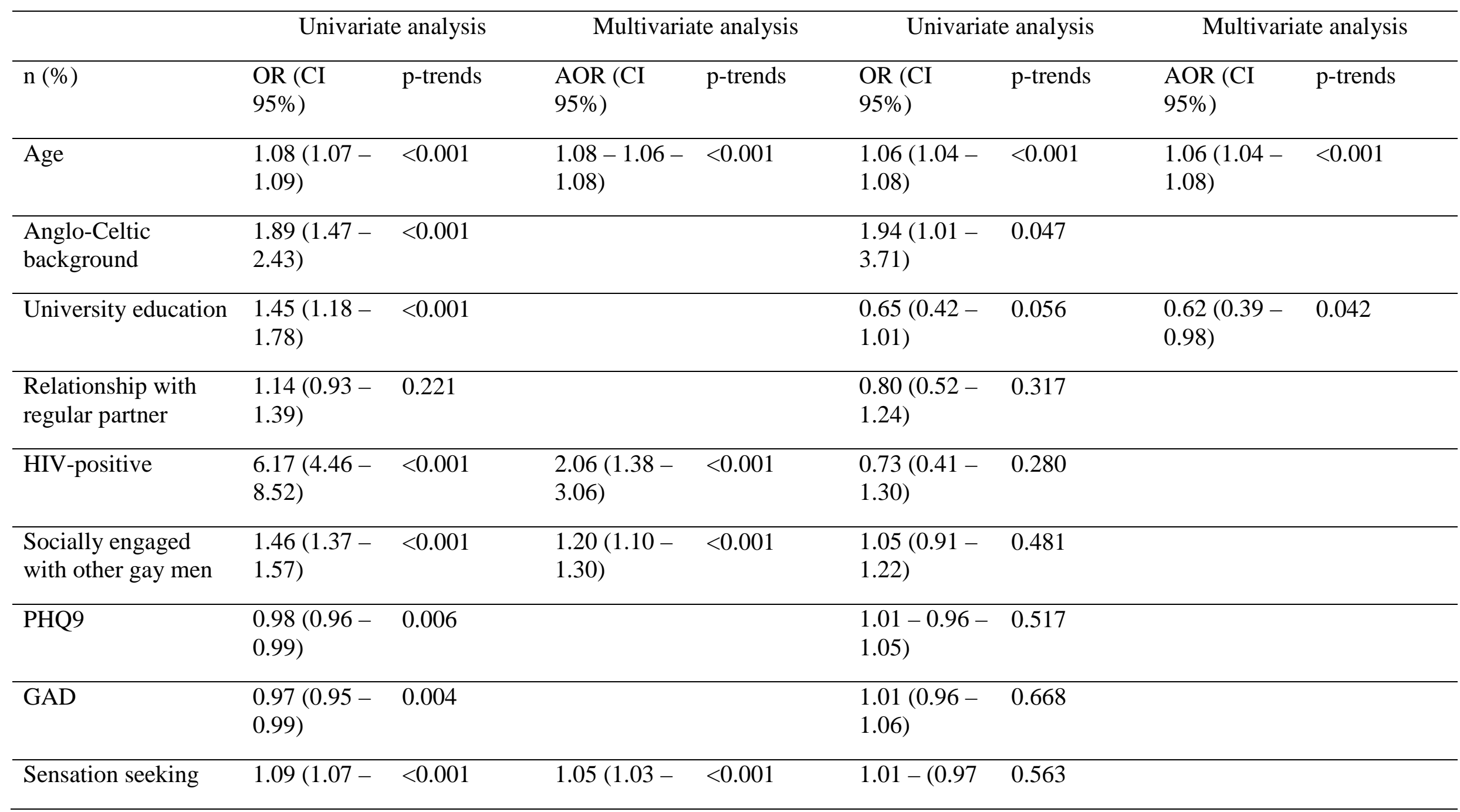




\begin{tabular}{|c|c|c|c|c|c|c|c|c|}
\hline scale & 1.11) & & 1.08) & & $-1.05)$ & & & \\
\hline Over 10 partners & $\begin{array}{l}3.39(2.74- \\
4.19)\end{array}$ & $<0.001$ & & & $\begin{array}{l}1.55(0.96- \\
2.41)\end{array}$ & 0.053 & & \\
\hline Group sex & $\begin{array}{l}4.08(3.28- \\
5.07)\end{array}$ & $<0.001$ & $\begin{array}{l}1.59(1.20- \\
2.120\end{array}$ & 0.001 & $\begin{array}{l}1.42(0.89- \\
2.26)\end{array}$ & 0.146 & & \\
\hline $\begin{array}{r}\text { Condomless anal } \\
\text { intercourse with } \\
\text { casual partners }\end{array}$ & $\begin{array}{l}2.89(2.34- \\
3.57)\end{array}$ & $<0.001$ & & & $\begin{array}{l}0.60(0.39- \\
0.94)\end{array}$ & 0.024 & $\begin{array}{l}0.59(0.37- \\
0.94)\end{array}$ & \\
\hline${ }^{\mathrm{a}}$ Used marijuana & $\begin{array}{l}1.51(1.21- \\
1.88)\end{array}$ & $<0.001$ & & & $\begin{array}{l}0.82(0.50- \\
1.32)\end{array}$ & 0.409 & & \\
\hline${ }^{\mathrm{a}}$ Used ecstasy & $\begin{array}{l}2.29(1.79- \\
2.92)\end{array}$ & $<0.001$ & & & $\begin{array}{l}0.60(0.35- \\
1.04)\end{array}$ & 0.068 & & \\
\hline $\begin{array}{r}{ }^{\mathrm{a}} \text { Used } \\
\text { meth/amphetamine } \\
\text { (speed) }\end{array}$ & $\begin{array}{l}1.75(1.19- \\
2.57)\end{array}$ & 0.004 & & & $\begin{array}{l}0.90(0.40- \\
2.01)\end{array}$ & 0.789 & & \\
\hline
\end{tabular}




\begin{tabular}{|c|c|c|}
\hline${ }^{\mathrm{a}}$ Used cocaine & $\begin{array}{l}2.33(1.78-<0.001 \\
3.07)\end{array}$ & $\begin{array}{l}0.69(0.38-0.218 \\
1.25)\end{array}$ \\
\hline $\begin{array}{l}{ }^{a} \text { Used crystalline } \\
\text { methamphetamine }\end{array}$ & $\begin{array}{l}7.64(5.82-<0.001 \\
10.04)\end{array}$ & $\begin{array}{l}0.875(0.54 \\
-1.42)\end{array}$ \\
\hline${ }^{a}$ Used GHB & $\begin{array}{ll}9.64(6.78-<0.001 \\
13.71)\end{array}$ & $\begin{array}{l}0.80(0.47-0.434 \\
139)\end{array}$ \\
\hline${ }^{a}$ Used LSD & $\begin{array}{ll}1.01(0.59- & 0.963 \\
1.75) & \end{array}$ & $\begin{array}{ll}1.15(0.37- & 0.814 \\
3.60) & \end{array}$ \\
\hline a Used heroin & $\begin{array}{ll}7.42(0.67- & 0.102 \\
82.03) & \end{array}$ & $\begin{array}{ll}3.84(0.24- & 0.343 \\
61.89) & \end{array}$ \\
\hline
\end{tabular}

${ }^{\mathrm{a}}$ Omitted from multivariate model due to possible multicollinearity. 